\title{
Commentary: Folk-Economic Beliefs: An Evolutionary Cognitive Model
}

\author{
Tobias Otterbring ${ }^{1,2 *}$ and Panagiotis Mitkidis ${ }^{3,4}$ \\ ${ }^{1}$ Department of Management/MAPP, Aarhus University, Aarhus, Denmark, ${ }^{2}$ Department of Psychology/CTF, Service \\ Research Center, Karlstad University, Karlstad, Sweden, ${ }^{3}$ Department of Management, Aarhus University, Aarhus, Denmark, \\ ${ }^{4}$ Center for Advanced Hindsight, Duke University, Durham, NC, United States
}

Keywords: lay beliefs, common sense, biases, behavioral economics, evolutionary psychology

\section{A commentary on}

Folk-Economic Beliefs: An Evolutionary Cognitive Model

by Boyer, P., and Petersen, M. B. (2017). Behav. Brain Sci. doi: 10.1017/S0140525X17001960 [Epub ahead of print].

More than half a century of research has documented that people's capacity to predict the actions, attitudes, and abilities of themselves and others is quite limited (e.g., Milgram, 1963; Nisbett and Wilson, 1977; Ariely and Loewenstein, 2006; Otterbring et al., 2018). Thus, although scholars have argued that people's common sense and their roles as naïve or intuitive psychologists (Heider, 1958; Ross, 1977) are great assets for theory building, several studies have shown that lay beliefs and other intuition-based predictions "are exaggerated at best, and wholly inaccurate at worst" (Kelley, 1992, p. 6). However, despite findings that lay beliefs, self-report measures, and individuals' intuitions are both unreliable and self-contradictory, and that common sense is an inherently dangerous resource for scholars to rely upon (Fletcher, 1984), there has been a call for more research on the distinction between beliefs and behaviors, between common-sense psychology and scientific psychology (Kelley, 1992).

In a recent paper, Boyer and Petersen (2017) attempt to demonstrate the importance and theoretical interest of lay beliefs, and call for further studies pertaining to this particular topic. While we agree with most of these authors' arguments, we would like to raise some critical points regarding: (1) Their "one-or-none" treatment of alternative accounts for the existence of laypeople's beliefs (based on ignorance, self-interest, and biases), and, more importantly, (2) Their claim that biases primarily constitute "proximate" how-explanations, as opposed to "ultimate" why-explanations, of various lay beliefs.

Firstly, we are not fully convinced with the way Boyer and Petersen (2017) address the alternative accounts of ignorance, self-interest, and biases. Specifically, we question that lay beliefs exist solely because of one of these sources, mainly because explanations based on ignorance or self-interest are not necessarily at odds with or different from explanations based on biases. In fact, many biases have ignorance (e.g., the overconfidence effect or the Dunning-Kruger effect) and/or self-interest (e.g., the self-serving bias) as their central common denominator (Ross et al., 1977; Bradley, 1978; Weinstein, 1980; Prentice and Miller, 1993; Babcock and Loewenstein, 1997; Lambert et al., 2003).

Taking that into consideration, we also disagree with the thesis that biases typically constitute only proximate explanations of laypeople's beliefs. In our view, a bias account can very well offer ultimate explanations of various lay beliefs. Consider the following examples. Researchers rate their own manuscripts as better than those authored by their peers; in fact, they even believe that their rejected manuscripts are at least as good as others' accepted manuscripts (Van Lange, 1999). Moreover, the majority of people think that they have better sex lives than average (de Jong and Reis, 2015), and that they are more intelligent, competent, and talented 
than most others (Dunning et al., 2004), especially if they score in the bottom quartile on tests measuring these abilities (Kruger and Dunning, 1999). A plausible ultimate explanation for these "better-than-average"-effects, as well as other self-viewbolstering biases (such as the optimism bias, the overconfidence effect, the egocentric bias, and the self-serving bias), is that it should have been adaptive for individuals, throughout human history, to feel good rather than bad about themselves. Hence, because people tend to portray themselves positively to defend, maintain, and enhance a favorable self-view (Cialdini et al., 1976; Greenwald, 1980; Greenberg and Pyszczynski, 1985), and since cognitive simplification mechanisms make it easier to accept information that confirms prior beliefs (Lord et al., 1979; Nüssler et al., 2018), the evolution of such ego-boosting biases most likely prevented our ancestors from developing a dehumanized dystopia, characterized by a pandemic state of depression. Instead, such biases presumably fostered a climate where we could thrive and survive (cf. Haselton and Nettle, 2006).

Rather than treating biases as idiosyncratic deviations, it may be more meaningful to perceive them as beliefs or behaviors that

\section{REFERENCES}

Ariely, D., and Loewenstein, G. (2006). The heat of the moment: The effect of sexual arousal on sexual decision making. J. Behav. Decis. Mak. 19, 87-98. doi: 10.1002/bdm.501

Babcock, L., and Loewenstein, G. (1997). Explaining bargaining impasse: the role of self-serving biases. J. Econ. Perspect. 11, 109-126. doi: 10.1257/jep.11.1.109

Boyer, P., and Petersen, M. B. (2017). Folk-economic beliefs: an evolutionary cognitive model. Behav. Brain Sci. doi: 10.1017/S0140525X17001960. [Epub ahead of print].

Bradley, G. W. (1978). Self-serving biases in the attribution process: a reexamination of the fact or fiction question. J. Pers. Soc. Psychol. 36, 56-71. doi: 10.1037/0022-3514.36.1.56

Cialdini, R. B., Borden, R. J., Thorne, A., Walker, M. R., Freeman, S., and Sloan, L. R. (1976). Basking in reflected glory: three (football) field studies. J. Pers. Soc. Psychol. 34, 366-375. doi: 10.1037/0022-3514.34.3.366

de Jong, D. C., and Reis, H. T. (2015). We do it best: commitment and positive construals of sex. J. Soc. Clin. Psychol. 34, 181-202. doi: 10.1521 /jscp.2015.34.3.181

Dunning, D., Heath, C., and Suls, J. M. (2004). Flawed self-assessment implications for health, education, and the workplace. Psychol. Sci. Public Interest 5, 69-106. doi: 10.1111/j.1529-1006.2004.00018.x

Fletcher, P. (1984). Psychology and common sense. Am. Psychol. 39, 203-213. doi: 10.1037/0003-066X.39.3.203

Goldstein, D. G., and Gigerenzer, G. (2002). Models of ecological rationality: the recognition heuristic. Psychol. Rev. 109, 75-90. doi: 10.1037/0033-295X.109.1.75

Greenberg, J., and Pyszczynski, T. (1985). Compensatory self-inflation: a response to the threat to self-regard of public failure. J. Pers. Soc. Psychol. 49, 273-280. doi: 10.1037/0022-3514.49.1.273

Greenwald, A. G. (1980). The totalitarian ego: fabrication and revision of personal history. Am. Psychol. 35, 603-618. doi: 10.1037/0003-066X.35.7.603

Haselton, M. G., and Nettle, D. (2006). The paranoid optimist: an integrative evolutionary model of cognitive biases. Personal. Soc. Psychol. Rev. 10, 47-66. doi: 10.1207/s15327957pspr1001_3

Haselton, M. G., Bryant, G. A., Wilke, A., Frederick, D. A., Galperin, A., Frankenhuis, W. E., et al. (2009). Adaptive rationality: an evolutionary perspective on cognitive bias. Soc. Cogn. 27, 733-763. doi: $10.1521 /$ soco.2009.27.5.733 evolved because they were "good enough" responses providing us with fast answers to specific situations (Goldstein and Gigerenzer, 2002; Todd and Gigerenzer, 2007), particularly those linked to survival and reproduction (Haselton and Nettle, 2006; Haselton et al., 2009). This conceptualization could offer a more unified way to explain the existence of various bias-based beliefs, and we therefore welcome the call for further scientific studies on this topic (Marshall et al., 2013) to elucidate the deep-rooted adaptive aspects of such beliefs.

\section{AUTHOR CONTRIBUTIONS}

TO lead-authored the article, with input from PM. Both authors approved the final version of the article prior to submission.

\section{ACKNOWLEDGMENTS}

This commentary is based on a portion of the first author's doctoral dissertation (Otterbring, 2017).
Heider, F. (1958). The Psychology of Interpersonal Relations. New York, NY: Wiley. Kelley, H. H. (1992). Common-sense psychology and scientific psychology. Annu. Rev. Psychol. 43, 1-24. doi: 10.1146/annurev.ps.43.020192.000245

Kruger, J., and Dunning, D. (1999). Unskilled and unaware of it: How difficulties in recognizing one's own incompetence lead to inflated self-assessments. J. Pers. Soc. Psychol. 77, 1121-1134. doi: 10.1037/0022-3514.77.6.1121

Marshall, J. A., Trimmer, P. C., Houston, A. I., and McNamara, J. M. (2013). On evolutionary explanations of cognitive biases. Trends Ecol. Evol. 28, 469-473. doi: 10.1016/j.tree.2013.05.013

MILGRAM, S. (1963). Behavioral study of obedience. J. Abnorm. Soc. Psychol. 67, 371-378. doi: 10.1037/h0040525

Lambert, T. A., Kahn, A. S., and Apple, K. J. (2003). Pluralistic ignorance and hooking up. J. Sex Res. 40, 129-133. doi: 10.1080/00224490309552174

Lord, C. G., Ross, L., and Lepper, M. R. (1979). Biased assimilation and attitude polarization: the effects of prior theories on subsequently considered evidence. J. Pers. Soc. Psychol. 37, 2098-2109. doi: 10.1037/0022-3514.37.11.2098

Nisbett, R. E., and Wilson, T. D. (1977). Telling more than we can know: verbal reports on mental processes. Psychol. Rev. 84, 231-259. doi: 10.1037/0033-295X.84.3.231

Nüssler, E. K., Nüssler, E., Eskildsen, J. K., Håkonsson, D. D., Löfgren, M., and Mitkidis, P. (2018). The influence of geographical and clinical factors on decisions to use surgical mesh. Total Quality Manag. Bus. Excell. doi: 10.1080/14783363.2018.1452610

Otterbring, T. (2017). A Shaken Self on Shopping: Consumer Threats and Compensatory Consumption. Doctoral Thesis. Karlstad University Studies 2017:6, Karlstad, Sweden.

Otterbring, T., Ringler, C., Sirianni, N. J., and Gustafsson, A. (2018). The Abercrombie and Fitch effect: the impact of physical dominance on male customers' status-signaling consumption. J. Market. Res. 55, 69-79. doi: 10.1509/jmr.15.0247

Prentice, D. A., and Miller, D. T. (1993). Pluralistic ignorance and alcohol use on campus: some consequences of misperceiving the social norm. J. Pers. Soc. Psychol. 64, 243-256. doi: 10.1037/0022-3514.64.2.243

Ross, L. (1977). The intuitive psychologist and his shortcomings: distortions in the attribution process. Adv. Exp. Soc. Psychol. 10, 173-220. doi: 10.1016/S0065-2601(08)60357-3

Ross, L., Greene, D., and House, P. (1977). The "false consensus effect": an egocentric bias in social perception and attribution processes. J. Exp. Soc. Psychol. 13, 279-301. doi: 10.1016/0022-1031(77)90049-X 
Todd, P. M., and Gigerenzer, G. (2007). Environments that make us smart: ecological rationality. Curr. Dir. Psychol. Sci. 16, 167-171. doi: 10.1111/j.1467-8721.2007. 00497.x

Van Lange, P. A. M. (1999). Why authors believe that reviewers stress limiting aspects of manuscripts: the SLAM effect in peer review. J. Appl. Soc. Psychol. 29, 2550-2566. doi: 10.1111/j.1559-1816.1999.tb 00125.x

Weinstein, N. D. (1980). Unrealistic optimism about future life events. J. Pers. Soc. Psychol. 39, 806-820. doi: 10.1037/0022-3514.39.5.806
Conflict of Interest Statement: The authors declare that the research was conducted in the absence of any commercial or financial relationships that could be construed as a potential conflict of interest.

Copyright $\odot 2018$ Otterbring and Mitkidis. This is an open-access article distributed under the terms of the Creative Commons Attribution License (CC BY). The use, distribution or reproduction in other forums is permitted, provided the original author(s) and the copyright owner are credited and that the original publication in this journal is cited, in accordance with accepted academic practice. No use, distribution or reproduction is permitted which does not comply with these terms. 